\title{
Laboreal
}

Volume 15 №2 | 2019

Varia

\section{Atuação de psicólogas na assistência social : relações entre gênero profissional e saúde}

Actuación de psicólogas en la asistencia social : relaciones entre género

profesional y salud

Actuation de psychologues en assistance social : relations entre genre

professionnel et santé

Performance of women psychologists in social assistance : relationships between professional gender and health

lasmin Libalde Nascimento e Thiago Drumond Moraes

\section{OpenEdition}

Journals

Edição electrónica

URL: http://journals.openedition.org/laboreal/15090

DOI: 10.4000/laboreal. 15090

ISSN: 1646-5237

\section{Editora}

Universidade do Porto

\section{Refêrencia eletrónica}

lasmin Libalde Nascimento e Thiago Drumond Moraes, " Atuação de psicólogas na assistência social : relações entre gênero profissional e saúde », Laboreal [Online], Volume $15 N^{0} 2$ | 2019, posto online no dia 01 dezembro 2019, consultado o 11 abril 2020. URL : http://journals.openedition.org/ laboreal/15090 ; DOI : https://doi.org/10.4000/laboreal.15090

Este documento foi criado de forma automática no dia 11 abril 2020.

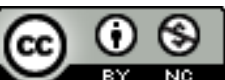

Laboreal está licenciado com uma Licença Creative Commons - Atribuição-NãoComercial 4.0 Internacional. 


\section{Atuação de psicólogas na assistência social : relações entre gênero profissional e saúde}

Actuación de psicólogas en la asistencia social : relaciones entre género

profesional y salud

Actuation de psychologues en assistance social : relations entre genre

professionnel et santé

Performance of women psychologists in social assistance : relationships between professional gender and health

lasmin Libalde Nascimento e Thiago Drumond Moraes

\section{NOTA DO EDITOR}

Manuscrito recebido em outubro/2018

Aceite após peritagem outubro/2019

\section{Introdução}

1 Este artigo apresenta o resultado do debate empreendido com um grupo de psicólogas que atuam na proteção social básica do Sistema Único de Assistência Social (SUAS) brasileiro acerca de sua atividade de trabalho e as reverberações desta na saúde das profissionais. As discussões foram guiadas pela perspetiva teórico-metodológica da Clínica da Atividade (CAt) (Clot, 2006), na qual a análise do trabalho surge como um dispositivo clínico com o objetivo de ampliar o poder de agir das profissionais, sobre elas mesmas e sobre seu campo de atuação, potencializando o coletivo de trabalhado e, com isso, intervindo na saúde laboral. o conceito de gênero profissional configura o cerne da discussão aqui proposta por permitir explicar alguns problemas que 
atravessam a atividade de trabalho das participantes assim como traçar pistas para promoção de saúde.

2 Cabe mencionar que, embora a CAt seja a referência desta pesquisa, durante as discussões será possível perceber o valor atribuído à vivência subjetiva das participantes. Nesse sentido, convém esclarecer que esse aspeto da análise que será aqui empreendida advém tanto das contribuições da própria CAt (Souto, Lima, \& Osorio-da-Silva, 2015), mas também por algumas inspirações dos modos como a teoria da psicodinâmica do trabalho (Dejours, 2004) tratam a questão. Considerou-se relevante apresentar essas questões devido à forte carga emocional que atravessou o diálogo das psicólogas sobre a atividade de trabalho em CRAS.

3 Embora as duas correntes teóricas utilizadas marquem pontos de divergência epistemológica e metodológica substanciais, convergem tanto pelo interesse em produzir condições nas quais os sujeitos possam se apropriar de sua atividade (Bendassolli \& Soboll, 2011), quanto por partilhar algumas heranças teóricas semelhantes, dentre as quais Canguilhem (2011) e Wisner (1994). Por essas razões, ainda que se identifiquem divergências, estas não impedem o debate entre tais abordagens teóricas sobre a atividade e sobre o trabalho. Portanto, durante as discussões posteriores, o trabalho também será considerado como uma "provação para a subjetividade da qual esta sai sempre ampliada, engrandecida ou, ao contrário, reduzida, mortificada. Trabalhar constitui, para a subjetividade, uma provação que a transforma" (Dejours, 2012, p. 34).

O SUAS, instituído pela Política Nacional de Assistência Social (PNAS) em 2004 no Brasil, reorganizou os serviços socioassistenciais por níveis de proteção, inaugurou a centralidade do Estado no acompanhamento às famílias, a territorialização das ações e a oferta de serviços da proteção social básica prioritariamente para famílias beneficiárias de transferência de renda (Brasil, 2005). Suas ações dividem-se por níveis de complexidade nos âmbitos da proteção social básica, que visa prevenir situações de risco pessoal e social, e proteção social especial, cujo serviço destina-se a pessoas que vivenciaram ameaça ou violação de direitos ou cuja convivência familiar mostra-se prejudicial para sua proteção e desenvolvimento (Brasil, 2005).

5 No Centro de Referência de Assistência Social (CRAS), unidade na qual são executados serviços de proteção social básica, a família usuária do serviço tem acesso a programas, projetos e benefícios que buscam promover a socialização, acolhimento, suporte para inserção no mercado de trabalho e fortalecimento dos vínculos sociofamiliares (Brasil, 2005). A equipe de referência mínima necessária para a realização das ações da proteção social básica é composta por um psicólogo, um assistente social, dois técnicos de nível médio, além de um coordenador de nível superior com experiência em gestão de serviços socioassistenciais (Brasil, 2009).

6 A inserção do profissional de psicologia como requisito para composição da equipe de referência mínima dos CRAS reflete a compreensão da importância de se trabalhar, simultaneamente, fatores psicológicos e sociais em contextos de risco e vulnerabilidade. Contudo, a recente entrada da profissão no campo da assistência social soma-se à imprecisão das prescrições institucionalizadas para a atuação do profissional de psicologia em CRAS, considerando que não especificam sua função nesse espaço (Flor \& Goto, 2015; Yamamoto \& Oliveira, 2010). Tal feito promove confusão para a os trabalhadores, que têm dificuldade em diferenciar sua atuação e a do assistente social, e 
para as instituições que parecem apresentar dificuldade em diferir o papel dos técnicos (Leão, Oliveira, \& Carvalho, 2014).

7 Para construir sua atividade profissional nesse espaço o psicólogo deve fazer frente à nebulosidade das prescrições (Flor \& Goto, 2015; Yamamoto \& Oliveira, 2010), à carência de referenciais teórico-metodológicos específicos para sua atuação (Yamamoto \& Oliveira, 2010) e às precárias condições de trabalho - com sobrecarga laboral, instabilidade dos vínculos empregatícios, falta de recursos humanos e materiais e remuneração insatisfatória (Leão et al., 2014 ; Macedo \& Dimenstein, 2012 ; Romagnoli, 2016). Para tanto, parece haver uma intensa mobilização subjetiva por parte dos profissionais, além da produção de um conhecimento próprio sobre o trabalho advindo da experiência prática, para que seja possível realizar sua tarefa. Ainda assim, Macedo e Dimenstein (2012) alegam que a vivência profissional do psicólogo nesses espaços é marcada por sensações como estranhamento, medo, impotência e frustração, além de um ressentimento quanto ao funcionamento dos serviços.

8 Em que momento a provável mobilização psicológica e o possível desenvolvimento de saberes por parte dos psicólogos em suas atividades cotidianas deixam de atuar como fatores produtores de saúde, neste contexto, é uma questão a se elucidar. A teoria da CAt em particular, somadas a algumas inspirações da psicodinâmica do trabalho, principalmente os modos como abordam as vivências subjetivas dos trabalhadores, apresentam-se como possíveis ferramentas para auxiliar no desvelamento de tais questões, sobretudo por possibilitar relacionar os modos de gestão das mobilizações coletivas diante das situações de trabalho e suas relações com processos de produção de saúde e/ou adoecimento.

\subsection{Atividade e subjetividade}

Para a CAt a atividade de trabalho está intrinsecamente vinculada à subjetividade. Essa perspetiva teórico-metodológica visa desenvolver o poder de agir dos profissionais "sobre o mundo e sobre si mesmos, coletiva e individualmente" (Clot, 2011, p. 72). Fundamenta sua atuação no estudo da perspetiva desenvolvimental da atividade, buscando analisar e desenvolver aspetos nos quais o trabalho constrói sentido e mobiliza a subjetividade dos profissionais de maneira que a singularidade do fazer de cada trabalhador possa ser construída a partir da atualização, frente à interpretação do real, de uma produção coletiva (re)vitalizada e, portanto, produtora de saúde (Clot, 2006).

Destaca-se nessa perspetiva o conceito de real da atividade de trabalho. Uma vez que o que se faz é somente uma ínfima parte de todos os possíveis que, por algum motivo, não foram realizados, o conceito de real da atividade é um avanço frente aos conceitos clássicos da ergonomia, tais como tarefa-atividade, trabalho prescrito-trabalho real (Clot, 2006). O trabalho prescrito pode ser definido como aquilo que os profissionais devem fazer segundo a organização do trabalho, e o trabalho real o que de fato se faz a fim de lograr a realização da tarefa. Entre o trabalho prescrito e o trabalho real, existe e persiste um oceano de possibilidades de ação em constante conflito que acabará por determinar o desenvolvimento da atividade vencedora (Fernández \& Clot, 2007). O conceito de real da atividade afirma que a atividade não se limita somente ao que é realizado : "o que não está feito, o que se pretenderia fazer, o que deve ser refeito e 
mesmo o que se faz sem se querer fazer, é acolhido na análise da atividade esclarecendo seus conflitos" (Clot, 2010, p. 149).

11 Ao se considerar o campo de possibilidades presentes no real da atividade e, ainda, a singularidade de cada trabalhador ao gerir a imprevisibilidade do meio a fim de realizar sua a tarefa, pode-se vislumbrar um leque, sempre em mutação, de possibilidades de se fazer a mesma tarefa. Segundo Clot $(2006,2010)$, é o coletivo de trabalho que se encarregará de validar e organizar as diferentes formas de saber-fazer o trabalho, constituídas em determinado espaço sócio-histórico para responder a demandas específicas, transformando-as em recurso para a realização da atividade.

12 Ao longo do tempo esse acumulado de recursos para a ação, mobilizado e construído pelo coletivo de trabalho, adquirirá um caráter histórico e irá retratar a memória laboral daquele coletivo profissional. Essa memória transpessoal e coletiva, que contribui com densidade e sentido para o fazer de cada trabalhador e do coletivo de trabalho, é o que Clot (2010) denomina de gênero profissional. Este gênero "contém a integralidade dos equívocos do trabalho coletivo, a memória dos fracassos, das perguntas sem resposta e das proezas realizadas, mas também as 'pequenezas' em que insistem o não realizado e o realizável em gestação" (Clot, 2010, p. 286).

o gênero profissional fornece um conjunto de normas e estratégias de ação maleáveis, que podem ser adaptadas pelo profissional durante seu fazer. O gênero, ao ser renovado continuamente a partir do trabalho coletivo do coletivo de trabalho, fortalece e respalda a atividade profissional (Fernández \& Clot, 2007). Quando o gênero profissional encontra-se enfraquecido, quando a produção desses previsíveis genéricos do trabalho encontra-se suspensa ou ausente, a saúde no ambiente de trabalho começa a se deteriorar e "cada um, individualmente, é confrontado, então, com surpresas ruins de uma organização do trabalho que o deixa 'sem voz' diante do real” (Clot, 2010, p. 171).

14 Segundo Clot (2010), a presença do gênero profissional e sua constante atualização pelo coletivo de trabalho é a chave para a produção de atividades de trabalho saudáveis. Uma ressalva, porém : reconhece-se que a construção genérica pressupõe a partilha de vivências cotidianas, o que não é o caso de boa parte dos psicólogos, que frequentemente atuam em seus serviços sem a presença de outros psicólogos ou, pelo menos, sem contar com pares em seus turnos de trabalho. 0 trabalho que executam é coletivo, sem dúvida, mas em partilha de espaços e situações de trabalho com profissionais de outras formações. Nesse sentido, no que tange ao direcionamento específico das atividades dos psicólogos, e dos modos de mobilizar seus saberes para as situações reais, parte-se da premissa que os processos saúde-doença envolvem não somente a dimensão genérica da construção realizada em partilhas de experiências do local de trabalho, mas, também, na incorporação de debates que são internos ao conjunto de atores de uma profissão em particular, como o dos psicólogos. Supõe-se, a partir daí, que a qualidade de um trabalho bem feito, e suas relações com o poder de agir, deve incorporar um debate constante com os pares e com os saberes, tanto locais quanto, em alguns casos, com pares não espacialmente presentes.

Reconhecemos aqui a importância da partilha das produções genéricas desenvolvidas nas experiências dos locais de trabalho, independente da formação acadêmicodisciplinar dos trabalhadores. Supõe-se, por exemplo, a existência de um gênero da atividade de trabalhadores dos CRAS, independente se psicólogos, assistentes sociais ou educadores. Contudo, essa pesquisa se debruçou sobre a compreensão das dimensões 
genéricas produzidas, ou não, entre pessoas de uma mesma formação profissional, no caso os psicólogos, que possuem, ou não, condições de partilhar, em seu dia-a-dia, essas experiências cotidianas da atividade de trabalho com outros trabalhadores da mesma formação profissional. Daí seu objetivo, a saber: identificar e analisar o gênero profissional de psicólogos que atuam na proteção social básica e sua relação com o processo de saúde/doença por eles vivenciados.

Já a psicodinâmica do trabalho, reconhecida essencialmente pelas idealizações de Cristophe Dejours, fundamenta-se nas contribuições da psicanálise, da ergonomia e da sociologia do trabalho. $O$ estudo da normalidade no trabalho coloca-se como um dos pontos centrais de investigação, sendo esta compreendida como "produto de uma dinâmica humana em que as relações intersubjetivas - na construção das estratégias defensivas, ou mesmo ofensivas, contra o sofrimento - ocupam um lugar central" (Dejours, 2004, p. 52). Em outras palavras, a normalidade resulta do equilíbrio instável e precário entre o sofrimento, que é inerente ao trabalhar, e as estratégias defensivas elaboradas enquanto recurso para enfrentamento e mediação desse sofrimento. Desta forma, a relação homem-trabalho é estudada do ponto de vista do normal e não apenas do patológico (Bendassolli \& Soboll, 2011 ; Dejours, 2004).

17 A psicodinâmica do trabalho compreende o homem enquanto sujeito cindido por conflitos intrapsíquicos, constituído sempre na relação com o outro ; e considera que os jogos de reconhecimento, que são fundamentalmente de natureza simbólica, são capazes de transmutar o sofrimento em prazer nas atividades de trabalho, uma vez que as dinâmicas de reconhecimento fornecem uma retribuição simbólica ao sujeito e contribuem para a produção de sentido à vivencia no trabalho. Ressalta-se que, para a teoria, o trabalho é compreendido como "a atividade manifestada por homens e mulheres para realizar o que ainda não está prescrito pela organização" (Dejours, 2004, p. 65), assumindo uma dimensão constitutiva do sujeito e, nesse sentido, basal nos processos de subjetivação. Desta feita, podemos dizer que a psicodinâmica do trabalho realiza uma análise "sociopsíquica do trabalho, tendo como ponto de partida a organização deste último, para então compreender as vivências subjetivas, dentre elas o prazer, o sofrimento, o processo saúde-adoecimento e os mecanismos de defesa e de mediação do sofrimento" (Bendassolli \& Soboll, 2011, p. 10).

\section{Método}

Haja vista a perspetiva teórico-metodológica adotada, principalmente a CAt, o presente estudo tem como foco de discussão o desenvolvimento da atividade de trabalho, para além de seu funcionamento prescrito. Assim, torna-se necessário a utilização de um método que se proponha a analisar aquilo que diante do real do trabalho os profissionais fazem com os desafios que emergem e as soluções encontradas, ou não, para confrontá-lo (Clot, 2006).

19 Nesse sentido, convém destacar a importância do coletivo de trabalho para a CAt, uma vez que ele se apresenta como recurso para o desenvolvimento da subjetividade individual. De facto, o coletivo "é uma das condições que favorecem o desenvolvimento de competências, na medida em que a sua vitalidade permite que se coloquem em debate maneiras de fazer, o que permite que elas evoluam" (Vidal-Gomel, Delgoulet, \& Geoffroy, 2014, p. 17). Por fim, envolve o compartilhamento de um conjunto de valores, 
formas de ser e de se relacionar com os outros e com os objetos, definindo com mais ou menos precisão o que é desejável ou não de fazer (Vidal-Gomel et al., 2014).

\subsection{Participantes}

Participaram da pesquisa cinco psicólogas que atuam em CRAS em Vitória-ES, no serviço de Proteção e Atendimento Integral à Família (PAIF). O PAIF é um serviço continuado de trabalho social com famílias que objetiva fortalecer os laços sociofamiliares, contribuindo para convivência, reconhecimento de direitos e construção de caminhos para o enfrentamento de questões que possam apresentar risco de rutura de vínculos e/ou violação de direitos no âmbito familiar ou comunitário (Brasil, 2009). Das psicólogas que compuseram o grupo de trabalho, duas atuam há um ano em CRAS, outras duas encontram-se no serviço por três anos e uma participante possui sete anos de trabalho na proteção social básica. Ademais, duas profissionais possuem vínculo empregatício por contrato temporário com a Prefeitura e as demais são vinculadas a uma Organização Não-Governamental.

21 A pesquisa foi autorizada pelo comitê de ética em pesquisas com seres humanos da UFES e que a anuência das trabalhadoras foi firmada mediante assinatura do Termo de Consentimento Livre e Esclarecido, pelo qual se autorizou a gravação dos encontros e sua posterior transcrição na íntegra.

\subsection{Instrumentos e procedimentos para a coleta das informações}

22 Como instrumento foi utilizado o método da oficina de fotos, que tem como objetivo instigar o profissional a refletir sobre sua atividade de trabalho rotineira. Em outras palavras, "a tarefa apresentada aos sujeitos consiste em elucidar para o outro e para si mesmo as questões que surgem durante o desenvolvimento das atividades" (Clot, 2006, p. 136).

Osorio-da-Silva, Pacheco e Barros (2013) sugerem que as fotos apresentam marcas da atividade que será analisada, contribuindo para produzir um distanciamento que abre espaço para diálogo consigo mesmo e com o gênero profissional. Este método possibilita que os trabalhadores se envolvam diretamente ao produzirem os retratos de seu trabalho (Alves \& Osorio, 2014). Além disso, para essas autoras, as fotos adotam uma perspetiva lúdica e que se torna mais próxima da realidade vivenciada pelos trabalhadores, deixando-os mais confortáveis para analisarem o trabalho sem que seja necessária a constante intervenção do pesquisador.

Os psicólogos de todos os doze CRAS do município de Vitória-ES foram convidados pessoalmente à construção coletiva e informados da permissão para sua liberação pela Secretaria Municipal de Assistência Social de Vitória. A atividade de pesquisaintervenção foi realizada na Universidade Federal do Espírito Santo (UFES), conforme a decisão do grupo. As reuniões aconteceram no período compreendido entre novembro e dezembro de 2015, subdivididas em quatro encontros quinzenais de duas horas, realizadas às sextas-feiras.

No primeiro encontro foram apresentados os objetivos da pesquisa e a perspetiva teórico-metodológica da CAt, buscando responder a possíveis dúvidas acerca da temática e dos objetivos da pesquisa. Realizou-se a apresentação das participantes e a 
discussão acerca de suas vivências enquanto psicólogas do PAIF e como compreendiam o papel e a atuação do psicólogo nos serviços de proteção social básica.

No segundo encontro o debate desenvolveu-se em torno da apresentação e pertinência do método proposto pela pesquisadora e da escolha dos temas compartilhados pelo grupo para realização da fotografia. As participantes validaram o método proposto, decidindo que seriam realizadas no mínimo três fotografias que representavam vivências positivas em seu trabalho, promovendo saúde laboral, e três fotografias de situações que despotencializavam sua saúde. Dentre as três fotos de cada categoria, duas seriam decididas em grupo e, no mínimo, uma seria realizada a partir da experiência singular de cada psicóloga. As participantes optaram por usarem seus próprios aparelhos celulares para registro das fotografias e enviá-las para a pesquisadora organizar a apresentação das produções, a fim de expô-las no terceiro encontro.

27 A escolha das fotos de situações negativas e positivas foi ancorada na experiência relatada por Osorio-da-Silva e colegas (2013) com profissionais da área de saúde. A opção pelo debate prévio das fotografias que representavam temas comuns a todas se deu por questões estratégicas, visto que algumas participantes relataram que a sobrecarga do serviço e/ou conflitos com a hierarquia poderiam dificultar a participação em todos os encontros. Nos terceiro e quarto encontros foram discutidas as fotografias de cada uma das participantes, suas semelhanças e diferenças e suas relações com as vivências no trabalho. Discutiu-se, igualmente, as questões construídas a partir da experiência de realização das fotos.

Vale ressaltar que a função da pesquisadora, no grupo, era de mobilizar um debate coletivo entre os trabalhadores, permitindo fazer circular a palavra entre os participantes. Sem conduzir o destino das conversas, esses encontros também foram inspirados na metodologia das Rodas de Conversa (Afonso \& Abade, 2008), cuja estratégia se constitui como metodologia participativa que propõe partir dos conhecimentos já construídos acerca de determinado assunto, buscando um processo de compreensão e de criação. Uma vez que o objetivo era colocar em evidência aspetos da atividade de trabalho das psicólogas em CRAS, tal metodologia apresentou-se como facilitadora do processo tendo em vista que "o que se busca na Roda não é uma disputa sobre "quem tem razão", mas a apreciação das diversas razões, o alargamento da visão de cada um, a ampliação dos horizontes e a possibilidade de melhor refletir sobre a questão abordada" (p. 24).

Em outras palavras, a metodologia proposta priorizou o debate em torno de uma temática, de modo a dar visibilidade às práticas relacionadas à vivência cotidiana que se relacionavam ao tema em debate. Por meio de tal dispositivo, possibilitou-se fluidez discursiva e negociações diversas entre as participantes. Assim, a partir da exposição de um tema, as pessoas apresentaram suas elaborações sobre ele, "sendo que cada uma instiga outra a falar, argumentando e contra-argumentando entre si, posicionando-se e ouvindo o posicionamento do outro" (Méllo, Silva, Lima, \& Di Paolo, 2007, p. 30). Os temas abordados nos encontros serão apresentados a seguir, quando forem descritos os resultados da presente pesquisa. 


\subsection{Análise de dados}

30 de Faïta (2005). A análise do discurso busca compreender os sentidos estabelecidos nas práticas discursivas, que podem ser verbais ou não-verbais. Assim, uma vez que a $A D$ não trabalha com o conteúdo específico do texto, mas com os sentidos produzidos, o pesquisador deve "estar atento ao silêncio, ao não verbalizado, ao que foi explicitamente incluído, ao tom da voz e, mesmo, às falas que se esvaziam de sentido para aquilo que está sendo discutido" (Macedo, Larocca, Chaves, \& Mazza, 2008). Segundo Faïta (2005), o pesquisador não deve considerar o texto por ele mesmo tampouco "buscar as correlações possíveis com situações ou acontecimentos extralinguísticos. $O$ texto obtido é apenas a imagem de um momento de uma história, de um processo complexo de onde recortamos um segmento" (Faita, 2005, p. 124).

31 No debate empreendido no grupo com psicólogas atuantes em CRAS, as trocas se desenvolveram de modo alternado entre questionamento, afirmação, crítica, comparação, etc., desencadeando um processo dialógico que desestabilizou alguns pressupostos que as participantes detinham no começo (Faïta, 2005), conforme será demonstrado ao longo do texto. Nesse sentido, o discurso das profissionais não deve ser entendido simplesmente como uma "instância de mediação de pensamentos e posições cognitivas do sujeito em direção a outros, mas o lugar onde se desenvolve um movimento específico desse pensamento" (Faïta, 2005, p. 57); o que permitiu um melhor manejo dos limites encontrados quando buscamos vislumbrar os meandros da atividade de trabalho.

O texto produzido a partir do registro dos encontros, serviu para mediar a relação entre a atividade de trabalho e a atividade discursiva das psicólogas. A "relação entre essas atividades, sua evolução e suas transformações elabora 'regimes de significação' próprios" (Faïta, 2005, p. 122), cabendo ao pesquisador reinterpretar os discursos tendo em conta, também, sua experiência nesse o processo.

33 Cabe mencionar, ainda, que as análises que se seguem podem dar a impressão de um enrijecimento do processo ocorrido. Entretanto, o que se buscou colocar em evidência foram as "grandes linhas da relação dialógica" (Faïta, 2005, p. 127) produzida nos encontros com as profissionais de psicologia e identificadas no processo de análise.

\section{Resultados e discussão}

Durante o segundo encontro foi discutido e acordado entre as participantes duas fotografias que retratavam aspetos considerados como negativos à sua saúde e duas fotos que se referiam a aspetos positivos. As fotografias que versavam sobre aspetos negativos foram : cesta básica e visita domiciliar (simbolizada por fotos da paisagem do território). A primeira foi elencada uma vez que, segundo as psicólogas, a presença de tal benefício implica risco de reprodução do assistencialismo pelo serviço. A foto também remete à dificuldade de se trabalhar tais questões junto à população atendida, visto que para elas muitos munícipes parecem compreender a função do CRAS somente como distribuição de cesta básica. A segunda foto refere-se ao risco corrido pelas profissionais ao entrarem no território para realização das visitas domiciliares durante conflitos entre gangues.

Laboreal, Volume 15 N$^{\circ} 2$ | 2019 
Os aspetos positivos de seu trabalho, evocados a partir das imagens, foram as visitas domiciliares e o grupo de trabalho (pesquisadora e psicólogas). A primeira faz alusão à importância, reconhecida pelas técnicas, de se fortalecer os vínculos com a família atendida, além da possibilidade de exercer sua atividade para além dos muros do CRAS. A segunda refere-se ao fato de que os encontros durante a pesquisa foram escolhidos por oportunizar a troca de experiências entre as participantes e o debate sobre sua atividade de trabalho.

Curiosamente, as fotografias individuais apresentaram forte similaridade, muitas vezes com o mesmo significado. Retratos de cadeira, ralo do banheiro, sala de atendimento e vale transporte, diziam da precarização das condições de trabalho. Duas participantes registraram o relatório quantitativo - instrumento de mensuração de atendimentos, enviado mensalmente à gestão - e a foto do Cadastro Único, expressando a gestão por metas e a exigência de produtividade. Uma participante fotografou a placa da coordenação, simbolizando o autoritarismo da gestão quanto às formas de atuar, que restringia e sufocava a profissional.

37 A equipe técnica foi retratada por todas as profissionais como um aspeto positivo de seu trabalho, referindo-se à importância do trabalho em equipe e ao apoio prestado pelas assistentes sociais para a realização de sua atividade. Também foram apresentadas fotografias que retratavam atividades com as famílias acompanhadas, simbolizando o valor dos debates e do processo grupal para as técnicas, como fortes instrumentos para luta por garantia de direitos e construção de vínculos comunitários.

As fotos serviram como dispositivo para que as diferentes formas de saber-fazer o trabalho pudessem ser atualizadas no discurso das profissionais, oportunizando seu confronto e produção de sentido compartilhado. Desta forma, as análises que se seguem apresentam um recorte das redes de significados e interconexões tecidas ao longo do complexo trabalho de se traduzir a atividade em palavra.

\section{1. "Falta tudo !"}

39 Em acordo com a literatura (Macedo \& Dimenstein, 2012; Romagnoli, 2016), as psicólogas relataram que a intensa rotatividade entre os trabalhadores se mostra prejudicial para a realização do serviço e para as atividades em equipe : "gente, teve mês esse ano que eu estava de férias e entrou uma técnica e saiu e eu nem conheci a técnica [...] E como você trabalha vínculo se a própria equipe não tem vínculo ?" (P10). As psicólogas definem a construção do vínculo com as famílias acompanhadas pelo PAIF como a base da produção do trabalho em CRAS, em conformidade ao PNAS (Brasil, 2005) que estabelece o fortalecimento de vínculos sociocomunitários e familiares como o eixo organizador das ações desenvolvidas nesse serviço. Porém, por se tratar de uma relação constituída na dimensão de afeto e confiança, muitas famílias evadem com a mudança de seu técnico de referência.

Para além da alta rotatividade, o discurso das profissionais também sinaliza um modelo de organização do trabalho definido por metas estipuladas pela gestão, corroborando com os resultados encontrados por Romagnoli (2016). Tal modelo, aliado a uma relação autoritária por parte da coordenação do serviço, com pouco espaço para diálogo, contribui para que algumas psicólogas se sintam pressionadas e, muitas vezes, se exponham ao risco : 
41 "Tem uma meta a cumprir, então, às vezes, se você não consegue localizar aquela família, você é pressionada estar buscando. [...] semana passada mesmo : 'Não, mesmo com tiro você vai subir' [fala da coordenadora do serviço]. E eu tinha que subir. [...] Assim, você sabe do seu compromisso, mas você também é um ser humano, você também fica apreensiva" (P1).

42 A rotatividade relatada pelas profissionais surge como efeito da precarização dos vínculos trabalhistas, definido por Franco, Druck, e Seligmann-Silva (2010) como a primeira dimensão da precarização do trabalho. Trata-se de um processo que envolve a perda de direitos trabalhistas, perdas salariais e produz uma desestabilização das referências de proteção social do trabalho, conduzindo à metabolização cotidiana da insegurança e da instabilidade: "terrenos em que prolifera e se move a gestão pelo medo" (p. 231).

O controle estabelecido a partir da instrumentalização do medo à demissão produz uma intensificação do trabalho, que se caracteriza por metas cada vez mais exigentes e ritmos de trabalho mais intensos, constituindo a segunda dimensão do processo de precarização laboral (Franco et al., 2010). Embora o medo à demissão não tenha surgido na fala das profissionais, tendo em vista a extrema competitividade e o atual cenário do mercado de trabalho brasileiro, podemos inferir que tal receio figura como um dos possíveis motivos pelos quais as técnicas, muitas vezes, arriscam sua segurança.

44 Ainda neste debate, outras estratégias foram confrontadas. A fim de evitar tal exposição ao risco, algumas psicólogas optam por não cumprir, ou ainda ocultar, que não realizam visitas domiciliares quando ocorre conflito no território, como sinaliza uma profissional : "você falando a questão da visita... a relação que eu tenho com a minha coordenadora hoje é uma relação assim. [silêncio] Mas, aí eu também me arrisco nesse sentido. O que acaba me adoecendo. Meu risco é não cumprir a meta" (P4). Percebe-se que tais "transgressões" às prescrições são realizadas de maneira solitária, na sombra e na inquietação, produzindo sofrimento para as trabalhadoras.

Clot (2010) ressalta que diante do enfraquecimento ou ausência do gênero profissional, dos previsíveis genéricos que mediam a gestão dos imprevisíveis do real do trabalho, os sujeitos são expostos ao isolamento. Assim, "cada um é individualmente confrontado, então, com surpresas ruins de uma organização do trabalho que os deixa 'sem voz' diante do real" (p. 171) e coloca em risco sua saúde, conforme é possível perceber na fala da participante.

O enfraquecimento do gênero profissional ocorre diante do mutismo do coletivo de trabalho, de seu esgotamento (Clot, 2010). A premissa de que existe um possível enfraquecimento do coletivo de trabalho dos psicólogos que atuam em CRAS é corroborada pela fala de uma das técnicas : “a gente teve um fórum de psicólogos há muito tempo atrás que foi... eu acho que foi o máximo! Que a gente conseguiu chegar na discussão. E depois agente regrediu" (P4). Pode-se dizer que a "regressão", mencionada pela participante, ocorreu uma vez que a manutenção da vivência social entre os sujeitos é imprescindível para que os esquemas técnicos, o confronto entre as construções singulares no fazer e a produção de um saber partilhado, não venham a se extinguir (Clot, 2006). Nesse sentido, supõe-se que a dissolução do fórum, que era um espaço formal de discussão sobre a atividade de trabalho, impactou profundamente o coletivo de trabalho desses profissionais, enfraquecendo-o. 
forum no qual os psicólogos dos CRAS de Vitória se reuniam para discutir sua atividade era realizado mensalmente, durante o expediente de trabalho. Os encontros iniciaram-se em 2008 e continuaram por dois anos. Entretanto, os efeitos de tais mobilizações terminaram por incomodar a gestão em vigor na ocasião, que dissolveu o grupo. Após o término das atividades de um dos encontros do grupo uma participante relata à pesquisadora que houve tentativas de reuniões informais : "Aí, aos poucos a gente voltou a fazer reunião de uma maneira muito informal e a gente acabou enfraquecendo e acabando" (P4).

Segundo Moraes e Athayde (2014) o coletivo de trabalho está intrinsecamente vinculado às atividades de trabalho de uma determinada profissão e constitui-se por meio dos relacionamentos, formais e informais, estabelecidos entre os trabalhadores. Ele é atravessado por afetos, sistemas de identificação profissional e partilha de valores, instigado em resposta aos "entraves, as exigências, as demandas das tarefas e das condições e formas de organização do trabalho" (p. 332). Nesse sentido, quando a participante menciona "a gente acabou enfraquecendo e acabando" (P4) para além do término do fórum, o "a gente" pode referir-se ao coletivo de trabalho. O que foi "acabando", esmorecendo-se a partir da dissolução do fórum de psicólogos de CRAS, pode-se conjecturar, foram os sistemas de identificação profissional que estavam sendo forjados.

Por fim, as participantes vivenciam falta de recursos humanos e materiais, precarização dos vínculos laborais, demonstram insatisfação com os salários e a necessidade, muitas vezes, de realizarem dupla jornada de trabalho para aumentar seus recursos, integrando o cenário exposto por outros estudos (Leão et al., 2014; Macedo \& Dimenstein, 2012 ; Romagnoli, 2016). Assim, "faltam recursos financeiros, cortaram um monte de colegas nossos que trabalhavam com a gente, falta tudo [grito]! o que não falta é presença de munícipe dentro da unidade, que continua só aumentando !" (P4).

50 Não obstante, a redução das equipes gera sobrecarga de trabalho para as psicólogas, conforme relato: "então, são 36 famílias, mais acolhida, mais as reuniões... e a assistente social está de férias. Então... aaahhhhh [grito]" (P11). Podemos dizer que o grito da participante se manifestou como expressão da angústia da necessidade de atuar em tal estado de precariedade. É um grito contido e que, embora não possa se manifestar em qualquer espaço, fez-se presente no grupo por lhe oportunizar elaboração.

51 Revelado não apenas como uma forma de desespero, o grito expressa-se como um movimento catártico que permitiu, em sequência, um segundo movimento de elaboração favorecido no e pelo grupo, tal qual este artigo posteriormente demonstrará. Assim, o discurso das profissionais nos sugere que as reverberações ocasionadas pelo desmantelamento do fórum de psicólogos atuantes em CRAS somaram-se à precarização dos vínculos empregatícios, da organização e das condições laborais, com a falta de recursos, intensificação dos ritmos e gestão por metas - o que dificulta em grande medida que as técnicas dialoguem entre si acerca de sua atividade de trabalho -, sustentando a hipótese do esmorecimento do coletivo de trabalho dessas profissionais. Nesse sentido, as participantes confrontam-se com o esgotamento dos recursos de ofício característicos de uma construção coletiva, o que somado à precarização de seu trabalho, parece contribuir para a diminuição do poder de agir dessas trabalhadoras e para a precarização de sua saúde. 


\subsection{E o nosso trabalho, para onde vai?}

52 Para além do que já fora mencionado, as participantes necessitam gerir aspetos contraditórios do serviço. As psicólogas do PAIF precisam cumprir metas de atendimento às famílias, sendo um dos objetivos dos serviços do CRAS o enfrentamento à vulnerabilidade (Brasil, 2005). Entretanto, diante da falta de recursos, rotatividade $\mathrm{e}$ redução da equipe, a meta de famílias para a obtenção dos benefícios e da verba necessária para manutenção das atividades algumas vezes não é atingida. Nesse sentido, mesmo que o objetivo do CRAS seja combater a vulnerabilidade, reduzindo o número de usuários do serviço, para se obter os recursos é necessário que haja um alto número de famílias cadastradas, o que se mostra paradoxal segundo as participantes :

"Você tem que combater aquilo [vulnerabilidade] mas ao mesmo tempo você precisa daquela pessoa para você ter o recurso. Gente, que viagem! Não dou conta, não dou conta [bate forte em alguma superfície], não dou conta!" (P1); “É, adoece !" (P8); "Adoece!" (P1); “Adoece!" (Grupo).

Cabe destacar que mesmo diante da ausência de recursos para a realização de suas tarefas, as profissionais continuam sendo cobradas a atingirem a meta de famílias cadastradas, necessária para a obtenção do recurso. Nesse sentido, as psicólogas demonstram revolta e frustração diante de tal necessidade. Sentem que a realização de sua atividade de trabalho é impedida, pois, de certa forma, necessitam que a família permaneça vinculada ao CRAS para que o serviço possa receber os recursos, em consonância com fala da técnica: "E o nosso trabalho, para onde vai? (P1) [Risos] ... [Silêncio] (Grupo)".

55 Para Clot (2006), na atividade de trabalho o sujeito exerce seu poder de recriação, ou seja, a atividade permite que o trabalhador produza um contexto para viver e constituise enquanto "fonte de uma espontaneidade indestrutível. Mesmo brutalmente proibida, nem por isso ela é abolida" (p. 14). Ao mesmo tempo potência criadora de vida e saúde, ela corre o risco de se desregrar e voltar-se contra o sujeito na medida em que o trabalhador, por mais que se tente, percebe-se impedido de realizar sua atividade ou é forçado a impedir-se de realizá-la, como parece ser o caso das psicólogas. "Quando chegam a isso, é ao preço de um insidioso esgotamento, de uma fadiga que é o ponto de partida para novos conflitos" (Clot, 2006, p. 15).

Interessante notar que em vários momentos as profissionais engasgam ou silenciam, o grupo silencia. Ao se analisar as situações nas quais ocorre o mutismo ou o entrave do discurso das psicólogas percebe-se que sempre se relaciona ao impedimento de sua atividade, seja por questões como definição rígida dos territórios de abrangência do CRAS, que muitas vezes dificulta sua atuação, ou pela imposição do cumprimento de metas, que para elas reduz a qualidade do serviço ofertado. Nesse sentido, a atividade travada, silenciada, amputada, manifesta-se também no discurso das profissionais que silenciam, gaguejam e engasgam quando atualizam e, consequentemente, (re)criam tais situações de trabalho no debate produzido durante os encontros do grupo de pesquisa (Clot, 2010).

57 As técnicas expõem que a falta de recursos exige que elas tenham de gerir a distribuição das cestas básicas, o que se mostra extremamente complexo e produtor de aflição, considerando que o cadastro no programa pressupõe que a família já se encontre em condições de extrema pobreza, segundo nota-se no excerto : 

de produção modos existir e de saúde (Schwartz, 2015), percebe-se que amputar o poder de agir das psicólogas é ferir aquilo que há de inestimável no trabalho. Diante disso, Clot (2010) acrescenta que o sujeito, na maioria das vezes, deixa de se reconhecer naquilo que faz, tendo em vista que os objetivos e metas que lhe são determinados diferem significativamente daquilo que é importante, que constitui sentido, para ele. Ora, diante do que já foi exposto até o presente momento, não surpreende que as profissionais relatem adoecimento e, como se verá a seguir, não se reconheçam enquanto psicólogas na assistência. Nesse sentido, a participante comenta : "Então, hoje eu acho que a gente tá tão perdido, a gente está tão esgotada, que a gente nem sabe o que está fazendo mais" (P4).

\subsection{A clínica da atividade enquanto clínica} restaurar a capacidade diminuída, ou seja, ampliar o poder de agir dos sujeitos, sobre o seu trabalho e sobre si mesmos, a partir do fortalecimento do coletivo de trabalho e do resgate ao gênero profissional. Nesse sentido, quando os sujeitos se deslocam de posição e passam a ter como objeto de análise seu trabalho, este último transforma-se e cria possibilidade de restauração da saúde.

Laboreal, Volume 15 N$^{\circ} 2$ | 2019 
64 Isto posto, pretende-se sinalizar a mudança no discurso das psicólogas ao longo dos encontros em direção ao início da produção de um (re)conhecimento profissional que encontrou voz no bojo da partilha e debate de normas, valores e estratégias que se mostraram pertinentes ou não para responder aos entraves da tarefa e/ou da organização do trabalho. Em outras palavras, aponta-se para o que parece ser um indício do desenvolvimento inicial de uma identificação desenvolvida e mediada pelos pares.

65 Conforme sinalizado anteriormente, as perceções sobre o papel do psicólogo em CRAS foram confrontadas no primeiro encontro. As profissionais afirmaram não se reconhecerem como psicólogas da proteção social básica, expressando dificuldade em se perceberem como profissionais de psicologia a partir de sua atuação na assistência. Ademais, informaram não saber qual seria o papel do psicólogo ou o que caracterizaria a especificidade de sua atuação profissional naquele espaço, conforme sinaliza a técnica :

66 "Eu entrei também com essa pergunta : o que faz o psicólogo no CRAS ? [...] E aí, quando começa a trabalhar, você vai ver que não existe uma identidade pro psicólogo. Que realmente é mais um ali para ajudar ; talvez com um olhar diferente. $E$ aí, tô lá há um ano, vai fazer um ano" (P8).

67 A fala das trabalhadoras vai ao encontro de estudos (Leão et al., 2014; Macedo \& Dimenstein, 2012) que indicam que os técnicos de psicologia não se identificam profissionalmente com o trabalho no SUAS, apresentando dificuldade em distinguir sua função da função do assistente social. Motta e Scarparo (2013) relatam que tal dificuldade também se expressa nas instituições, que não compreendem com clareza o papel e as atribuições do psicólogo, o que corrobora com a fala das participantes :

“Aí, a gente se perde. Por que esse profissional no CRAS, ele se perde pelo próprio fazer do CRAS. [...] na prática, e a gente ouve o tempo inteiro, né, sempre tem um coordenador, um gerente, um gestor, que fala assim: 'vocês fazem a mesma coisa' [referindo-se ao psicólogo e ao assistente social]" (P4).

69 Algumas participantes mencionaram sentirem-se inseguras quanto à sua atuação, haja vista o atual déficit de debates e produções construídas e compartilhadas coletivamente pelos psicólogos atuantes nos CRAS em Vitória, a carência de referências teóricometodológicas específicas (Yamamoto \& Oliveira, 2010) e a nebulosidade das prescrições. Uma psicóloga diz: "você está sozinha. Enfim, tem coisas que vão atrapalhando o andamento, vamos dizer assim. Mas, assim, eu às vezes fico meio na dúvida. Será que tá legal ? Será que eu poderia estar fazendo mais? Será que a limitação é minha ?" (P1).

70 Subsidiados por outras pesquisas (Flor \& Goto, 2015; Silva \& Corgozinho, 2011; Yamamoto \& Oliveira, 2010) que são atravessadas pelas mesmas questões, pode-se dizer que a nebulosidade das orientações (Brasil, 2009) que definem as atribuições de um técnico de referência que atua em CRAS contribui para a incerteza demonstrada pelas trabalhadoras e pela gestão do serviço. Nesse sentido, Flor e Goto (2015) colocam que "reuniões entre os psicólogos dos CRAS, discussões e até mesmo supervisões do fazer psicológico" (p. 31) poderiam auxiliar os profissionais a regularem tal defasagem, entretanto, apontam a inexistência de tais espaços de construção coletiva.

71 Ora, Clot (2006) afirma que o gênero profissional, construído e renovado no seio do trabalho de discussão e organização empreendido pelo coletivo de trabalho, fornecerá 
os subsídios necessários para que os profissionais encontrem segurança para enfrentar a assimetria entre a prescrição e o real do trabalho. $O$ gênero, transmutado em instrumento na atividade in situ, permitirá que o técnico acesse "procedimentos, organização do tempo, linguagem de ofício, organogramas, instrumentos técnicos, planos, regras implícitas, mas também todas as metáforas gestuais e verbais que conservam a memória das emoções de um meio de trabalho" (Clot, 2006, p. 154). Não obstante, no gênero encontra-se a sedimentação da experiência da atividade de trabalho coletiva, forjada ao longo da história daqueles trabalhadores. Essa memória tanspessoal e sócio-histórica do ofício, aglutina as marcas constitutivas e simbólicas, formas de ação e interpretação do mundo, ampliando o poder de agir dos trabalhadores e dotando de sentido e significado a atividade laboral.

Retomando o que foi discutido em um tópico anterior, pode-se conjeturar que a fragilidade do coletivo de trabalho dos psicólogos que atuam em CRAS dificulta em grande medida a manutenção e renovação de um patrimônio coletivo, dos pressupostos genéricos da atividade, favorecendo a construção do sentimento de solidão relatado pela psicóloga. Conforme Clot (2006) argumenta, quando o sujeito se encontra isolado de um coletivo de trabalho, na maioria das vezes, torna-se penoso saber por onde começar a desenvolver sua atividade. Assim, desassistidos frente às imprevisibilidades do real do trabalho, os indivíduos são levados a construir sua atividade sozinhos, a errar sozinhos, e a alcançar as metas e os objetivos impostos pela organização do trabalho ao preço custoso de sua saúde (Clot, 2006). Diante disso, talvez se possa compreender a dificuldade que as psicólogas expressam de se reconhecerem em sua atuação na proteção social básica e relatarem adoecimento.

Não obstante, as psicólogas realizam seu trabalho no contexto no qual ele se constrói e esforçam-se a fim de atingir as metas e conquistar, mesmo assim e apesar de tudo, os objetivos traçados pela PNAS. Embora afirmassem não saber o papel do psicólogo em CRAS, ao começarem a debater sobre sua atividade de trabalho - o que faziam, como faziam, o que não conseguiam fazer, o que gostariam de fazer - a partir de exemplos de sua atuação, foram tecendo aos poucos o fazer psicológico na proteção social básica.

74 Embora inicialmente não pudessem formular seu papel naquele espaço, a partir de exemplos de sua atividade foi possível perceber que, para as profissionais, cabe ao psicólogo em CRAS articular a realização do trabalho social junto aos demais serviços da rede socioassistencial, construir e fortalecer vínculos sociofamiliares, mediar o diálogo intrafamiliar e trabalhar as potencialidades de seus membros, visando superar sua situação de vulnerabilidade socioeconômica, além de colaborar com a construção de processos de mobilização política e social dos usuários. Nesse sentido, percebe-se que as auto-prescrições construídas pelas profissionais no tocante ao papel do psicólogo vai ao encontro do que é proposto na Nota Técnica com Parâmetros para a Atuação Profissional do Psicólogo no SUAS, elaborada pelo Conselho Federal de Psicologia (2016).

75 Ainda se destaca que a concessão de benefícios eventuais e a realização do cadastro socioeconômico não foram citadas pelas profissionais durante os exemplos que emergiram ao longo do debate. Lima (2014), ao realizar a análise das significações sobre a especificidade do trabalho de psicólogos na assistência social, aponta a resistência desses profissionais em assumir atividades que envolvam o atendimento de demandas explicitamente econômicas. Segundo o autor, os psicólogos consideram que o trabalho com dimensões objetivas do serviço prestado, como a concessão de benefícios 
socioassistenciais e cestas-básicas, corrobora com o assistencialismo e carece de importância se comparado ao trabalho com aspetos subjetivos, como o desenvolvimento de autonomia junto aos usuários do serviço e a reconstrução de aspetos subjetivos de suas vidas.

De fato, ainda que a tarefa de prestar serviços de concessão de benefícios a partir de aspetos socioeconômicos da vidas das pessoas não tenha sido mencionada na discussão sobre o papel do psicólogo em CRAS, as participantes realizam tais tarefas por estarem prescritas como funções de um técnico da assistência social (Brasil, 2009), conforme se percebe nos tópicos anteriormente descritos. Diferente do que destaca Lima (2014), infere-se que tais tarefas não surgiram nos exemplos das profissionais, não pelo fato de elas ignorarem sua importância ou pensarem que ao concederem o benefício estão corroborando com o assistencialismo, mas por existir uma carência de referências que orientem o papel de psicólogos nessas situações (Silva \& Corgozinho, 2011 ; Yamamoto \& Oliveira, 2010).

Além disso, a ausência de um espaço formal de discussão, ou mesmo a dificuldade encontrada pelas técnicas de dialogarem sobre sua atividade de trabalho ao nível interpessoal, devido à intensa carga de trabalho, prejudica em grande medida que as trabalhadoras possam, elas mesmas, construírem um saber que abarque tais questões e possa, assim, contribuir para a identificação profissional com tais tarefas. Ao se amputar espaços de discussão sobre o trabalho ou embaraçar, de uma forma ou de outra, o diálogo entre os profissionais acerca de sua atividade, restringe-se as vias que permitem formalizar um saber que é próprio da experiência, mas que, de modo algum, é ausente de preparo, de possibilidades (Faïta, 2005).

78 Apesar dessas falas iniciais, chama-se a atenção para a mudança no discurso das participantes ao longo dos encontros em direção à construção de uma identificação partilhada pelo grupo, no que se refere aos psicólogos de CRAS. No primeiro encontro, a fala das técnicas era direcionada aos CRAS nos quais elas atuavam. Assim, quando diziam "a gente" se referiam à equipe técnica do CRAS; seus exemplos e falas dificilmente eram generalizados em direção a um discurso que pudesse dizer daquele grupo de psicólogas da proteção social básica. O relato construía-se a partir da experiência pessoal enquanto psicóloga em CRAS, sinalizando isso com falas como "eu", "isso pra mim", "é a minha experiência, tá gente", ou então, retratavam a equipe técnica : "a gente".

79 Entretanto, a partir da metade do segundo encontro, o "a gente" passou a refletir as psicólogas que atuam em CRAS, suas falas passaram generalizar a experiência laboral daquele grupo. Começaram a interromperem-se umas às outras, completando frases sobre situações de trabalho e sentimentos que atravessavam a vivência naquele espaço. A perceção de que compartilhavam uma mesma linguagem e eram atravessadas por sentimentos semelhantes, no que tange à atuação, foi recebida com surpresa e empolgação. Nesse trecho a participante exemplifica a dificuldade em gerir a concessão de cestas básicas a partir de um episódio vivenciado por ela durante um atendimento individual, sendo logo interrompida, em sequência, pela fala de outras colegas que complementavam seu discurso :

80 "Olha, a gente não tem cesta. Eu não estou negando. É que a gente não tem cesta. Mas, assim, elas [as usuárias do serviço] não deixavam de ir. Podia reclamar, mas não deixavam de ir. Mas aí, com aquele monte de cestas que chegaram no início do ano, virou parece que uma obrigação" (P1); “e parece que a gente mentiu" (P4); “É! É ! 
[grito] Depois cai em cima também : "poxa, tem tanta cesta..." (P1); "porque como é a gente que escolhe, às vezes eles [os usuários do serviço] ficam na dúvida será que não tem mesmo ? Por que não me deram ?" (P8).

81 Pode-se dizer que a perceção desses sentimentos e vivências, partilhada pelo grupo de psicólogas, foi possível a partir das discussões provocadas na oficina de fotos. As participantes sugeriam uma imagem símbolo ou, então, situações de trabalho a serem fotografadas, que seriam validadas ou não no movimento dialógico dos encontros. Mobilizadas a justificar a escolha do retrato, elas deslocavam-se de posição colocando em análise sua atividade laboral (Alves \& Osorio, 2014). Assim, a partir do confronto entre suas vivências singulares, as participantes puderam perceber que compartilhavam algo em comum além de realizarem as mesmas tarefas no CRAS. Podese inferir que o processo vivenciado no/pelo trabalho do grupo de pesquisa propiciou o terreno para construção de um senso de compartilhamento de sentimentos, anseios, estranhezas, entraves e também conquistas que as atravessavam enquanto profissionais de psicologia atuantes na assistência. Vemos assim que mesmo sem a partilha das experiências da atividade in situ, as profissionais vivenciam situações semelhantes cotidianamente, o que as permitiu construir reflexões em comum, contribuindo para esse exercício de uma construção genérica das experiências de psicólogos de CRAS. Por outro lado, e considerando-se que há nos CRAS trocas de saberes e experiências entre profissionais de formações as mais diversas, deve-se supor a existência de produções genéricas mais transdisciplinares visando o funcionamento do serviço. As relações entre as dimensões do gênero produzido a partir da partilha das situações de trabalho com profissionais que trabalham in situ e as dimensões genéricas relacionadas aos conhecimentos disciplinares na atividade profissional podem ter relações com o poder de agir e a produção de saúde dos trabalhadores (Duarte \& Moraes, 2016). A maneira como tais relações ocorrem nos CRAS não foi devidamente investigada nessa pesquisa. De todo modo, vale observar que o poder de agir é atravessado por uma polifonia de vozes (Bezerra, 2012), oriundos de vários estratos distintos, que dialogam e se debatem o tempo inteiro.

Interessante observar que a produção dessa identificação entre as psicólogas, partilhada pelo grupo, se produziu também por meio do discurso das profissionais. Ao longo das construções, o debate da fotografia das visitas domiciliares propiciou a discussão acerca da territorialização dos CRAS que, embora necessária, define limites rígidos para as participantes e usuários do serviço, o que restringe sua atuação. Destarte, a mudança do "eu" para o "nosso" pode ser percebida no fragmento que se segue : "é complicado eu... Eu...Argh... Essas coisas... Essas coisas... Essas pontuações da gestão são necessárias. Eu acho que o meu.... A nossa... O meu... Eu falo a nossa compreensão enquanto psicólogo ! Isso acaba amarrando demais !" (P1).

83 Convém sinalizar que as participantes relataram que após os encontros, realizados às sextas-feiras, reuniam-se para confraternizar em um local próximo à universidade : "Da última vez nós saímos daqui fomos no Bar Boteco [nome fictício do estabelecimento]" (P8). Possivelmente, tais encontros possam explicar o motivo pelo qual as fotos individuais representaram as mesmas situações de trabalho.

84 Ao final dos encontros, retomou-se a pergunta inicial de como elas interpretavam o papel do psicólogo em CRAS. Curiosamente, as participantes responderam de forma similar ao primeiro encontro, ou seja, relataram dificuldade em sinalizar uma resposta 
para tal questão. Entretanto, quando a pesquisadora apontou as construções realizadas ao longo das discussões, o sentimento foi de espanto conforme observa-se no trecho :

"Eu queria saber como vocês avaliam isso que eu falei" (Pesquisadora); "Eu... Eu nem sei falar [risos]" (P10) ; "Acho que é por isso que a gente valorizou tanto espaço. Que a gente falou 'ai que bacana!' Que é aqui que a gente consegue reforçar e reafirmar isso. Você falando agora eu pensei assim ‘não, gente !"” (P4); “É ! Eu sou psicólogo! [grito]" (P10); "Então assim, ouvir as meninas a gente conversando... Desde o primeiro encontro, nossa, dá muito gás! Até para gente conseguir se organizar. Porque quando a gente vai para a prática parece que tudo tende a se destruir e, aqui, parece que a gente consegue juntar os nossos caquinhos, assim ..." (P4); "Sim! E aí as meninas falavam umas coisas e eu voltava para o CRAS pensava 'vou fazer isso também!' então, assim, me engrossava!" (P10).

A partir da fala das profissionais, podemos perceber que o "a gente" refere-se ao grupo de psicólogas. Ademais, inferimos que ao colocar "que é aqui que gente consegue reforçar e reafirmar isso" (P4), a participante sinaliza que aquilo que se reafirma e reforça pelo trabalho coletivo de discussão da atividade de trabalho é o reconhecimento de si mesmas, como profissionais de psicologia, naquilo que fazem na assistência social. Os encontros criaram espaço para que fosse possível que as técnicas partilhassem formas diversas de se pensar e fazer o trabalho psicológico na proteção social básica, estratégias construídas frente ao real e a vivência de sentimentos e anseios a partir de uma linguagem comum, transformando-os em recurso para ação (Clot, 2006, 2010).

Nesse sentido, os encontros "engrossavam" as profissionais uma vez que possibilitavam a ampliação de sua capacidade de agir. Restaurar a capacidade diminuída, "juntar os caquinhos" dos trabalhadores, contribuindo para aumentar seu poder de agir sobre trabalho, potencializa produção de saúde laboral (Clot, 2010).

\section{Conclusão}

Pode-se dizer que as condições de trabalho e a fragilidade do coletivo profissional, na construção e renovação dos pressupostos genéricos da atividade de trabalho, constituíram as bases para o adoecimento relatado pelas psicólogas no presente estudo. Em síntese, as técnicas vivenciam tanto um desgaste afetivo, com a experiência de sentimentos de ansiedade, frustração, impotência e insegurança, corroborando com o trabalho de Macedo e Dimenstein (2012), quanto um desgaste físico devido à necessidade de realizarem as visitas domiciliares de ônibus e, muitas vezes, caminhando : "falando de adoecimento do corpo, eu estou com meu joelho direito que falhou duas vezes numa escadaria lá. Eu falei : 'gente, eu preciso ir no médico !"” (P8).

Conforme demonstrado ao longo deste trabalho, as imagens fotográficas serviram como dispositivo para disparar diálogos sobre a atividade de trabalho em CRAS. As participantes puderam trocar informações e confrontar estratégias produzidas de forma solitária para enfrentar o real da atividade, validando-as ou não. Tal feito contribuiu para "ampliar o repertório de possibilidades de compreender e de agir na situação de trabalho, desenvolvendo a atividade" (Souto et al., 2015, p.14) e potencializando a produção de saúde. Ademais, inferimos que a partir dos diálogos se construiu um sentido sobre o trabalho do psicólogo em CRAS, compartilhado pelo 
grupo. Tal produção dialógica foi demonstrada no discurso das profissionais no terceiro movimento de análise.

Depreende-se que se fosse possível a expansão e permanência de tais encontros sobre o trabalho, "pelo fato de passar de mão em mão e de boca em boca" (Clot, 2011, p. 76) ao longo do tempo os saberes, vivências e formas do fazer laboral, construídas e compartilhadas no coletivo de trabalho, iriam renovar sua dimensão genérica e produzir junto aos trabalhadores o sentimento de viver uma mesma história. Somente a partir do trabalho de debate do coletivo de trabalho ao longo do tempo, torna-se possível construir e renovar continuamente um plano de referência genérico que oriente a ação e produza sentido para um grupo profissional (Clot, 2006). Em outras palavras, a possibilidade de fortalecer e manter vivo o gênero profissional permite aos trabalhadores se reconhecerem em sua atuação e nos resultados obtidos, assim como no que produzem de si mesmos em sua atividade de trabalho (Clot, 2010).

Não obstante, a partir do discurso das participantes - da experiência de solidão durante a atuação, vivência de insegurança e da sensação de não se reconhecerem como profissionais de psicologia naquilo que fazem na assistência social - pode-se dizer que essa dimensão genérica do trabalho de psicólogos de CRAS, para além da dimensão genérica de trabalho na assistência social, encontra-se extremamente enfraquecida o que produz, junto à precarização do trabalho, o adoecimento das técnicas. Entretanto, por meio de experiência apresentada neste artigo, sugere-se que o fortalecimento do coletivo de trabalho, que desenvolve e renova o gênero profissional, possibilita a produção de recursos que potencializam da saúde do trabalhador.

\section{BIBLIOGRAFIA}

Afonso, M. L., \& Abade, F. L. (2008). Para reinventar as rodas : rodas de conversa em Direitos Humanos. Belo Horizonte : RECIMAM.

Alves, E. A., \& Osorio, C. (2014). Clínica da atividade e oficina de fotos : eletricistas em foco. Revista Psicologia e Saúde, 6(2), 62-71. doi : 10.20435/pssa.v6i2.360

Bendassolli, P. F., \& Soboll, L. (2011). Introdução às clínicas do trabalho : aportes teóricos, pressupostos e aplicações. In P. F. Bendassolli, \& L. Soboll (Eds.), Clínicas do Trabalho : novas perspectivas para compreensão do trabalho na atualidade (pp. 3-21). São Paulo : Atlas.

Bezerra, P. (2012). Polifonia. In B. Brait (Ed.), Bakhtin : conceitos-chave (pp. 191-200). São Paulo : Editora Contexto.

Brasil (2005). Política Nacional de Assistência Social (PNAS/2004). Norma Operacional Básica (NOB/SUAS). Brasília : Ministério do Desenvolvimento Social e Combate à Fome.

Brasil (2009). Orientações técnicas : Centro de Referência de Assistência Social (CRAS). Brasília : Ministério do Desenvolvimento Social e Combate à Fome.

Canguilhem, G. (2011). O normal e o patológico. Rio de Janeiro : Forense Universitária.

Clot, Y. (2006). A função psicologica do trabalho. Petrópolis : Vozes. 
Clot, Y. (2010). Trabalho e poder de agir. Belo Horizonte : FabreFactum.

Clot, Y. (2011). Clínica do trabalho e clínica da atividade. In P. F. Bendassolli \& L. Soboll (Eds.), Clínicas do trabalho (pp. 71-83). São Paulo : Atlas.

Conselho Federal de Psicologia. (2016). Nota Técnica com Parâmetros para atuação das e dos profissionais de Psicologia no âmbito do Sistema Único de Assistência Social (SUAS) (2016). Brasília : Autor.

Dejours, C. (2004). Addendum : da psicopatologia à psicodinâmica do trabalho. In S. Lancman, \& L. I. Sznelwar (Eds.), Christophe Dejours : da psicopatologia à psicodinâmica do trabalho (pp. 47-104). Rio de Janeiro : Editora Fiocruz, Paralelo 15.

Dejours, C. (2012). Trabalho vivo : trabalho e emancipação (Vol. 2). Brasília : Paralelo 15.

Duarte, L. C., \& Moraes, T. (2016). Saúde mental de psicólogos atuantes em serviços de atenção primária à saúde. Estudos Interdisciplinares em Psicologia, 7(2), 123-146. doi :

10.5433/2236-6407.2016v7n2p123

Faïta, D. (2005). Análise dialógica da atividade profissional. Rio de Janeiro : Imprinta Express Editora.

Fernández, G., \& Clot, Y. (2007). Entrevistas de auto-confrontação : um método na clínica da actividade. Laboreal, 3(1), 15-19. doi : 10.4000/laboreal.12782

Flor, T. C., \& Goto, T. A. (2015). Atuação do psicólogo no CRAS : uma análise fenomenológicoempírica. Revista da Abordagem Gestáltica, 21(1), 22-34.

Franco, T., Druck, G., \& Seligmann-Silva, E. (2010). As novas relações de trabalho, o desgaste mental do trabalhador e os transtornos mentais no trabalho precarizado. Revista Brasileira de Saúde Ocupacional, 35(122), 229-248. doi : 10.1590/S0303-76572010000200006

Leão, S. M., Oliveira, I., \& Carvalho, D. (2014). O Psicólogo no Campo do Bem-Estar Social : atuação junto às famílias e indivíduos em situação de vulnerabilidade e risco social no Centro de Referência de Assistência Social (CRAS). Estudos e Pesquisas em Psicologia, 14(1), 264-289.

Lima, V. C. (2014). A psicologia da pobreza e a pobreza da psicologia (Dissertação de Mestrado). Pontifícia Universidade Católica de São Paulo, São Paulo, Brasil.

Macedo, J. P., \& Dimenstein, M. (2012). O trabalho dos psicólogos nas políticas sociais no Brasil. Avances en Psicología Latinoamericana, 30(1), 182-192

Macedo, L. C., Larocca, L., Chaves, M., \& Mazza, V. (2008). Análise do discurso : uma reflexão para pesquisar em saúde. Interface - Comunicação, Saúde e Educação, 12(26), 649-657. doi : 10.1590/ S1414-32832008000300015

Méllo, R. P., Silva, A., Lima, M. , \& Di Paolo, A. (2007). Construcionismo, práticas discursivas e possibilidades de pesquisa em psicologia social. Psicologia \& Sociedade, 19(3), 26-32. doi : 10.1590/S0102-71822007000300005

Moraes, T. D., \& Athayde, M. (2014). Dimensões do coletivo na atividade de trabalho dos motoboys. Fractal, 26(2), 327-348. doi : 10.1590/1984-0292/906

Motta, R. F., \& Scarparo, H. (2013). A psicologia na assistência social : transitar, travessia. Psicologia \& Sociedade, 25(1), 230-239. doi : 10.1590/S0102-71822013000100025

Osorio-da-Silva, C., Pacheco, A., \& Barros, M. (2013). Oficinas de fotos : experiências brasileiras em clínica da atividade. Cadernos de Psicologia Social do Trabalho, 16, 121-131. doi : 10.11606/issn. 1981-0490.v16ispe1p121-131 
Romagnoli, R. C. (2016). Relações macropolíticas e micropolíticas no cotidiano do CRAS. Psicologia \& Sociedade, 28(1), 151-161. doi : 10.1590/1807-03102015v28n1p151

Schwartz, Y. (2015). Manifesto por um ergoengajamento. In Y. Schwartz \& L. Durrive (Eds.), Trabalho e ergologia II : diálogos sobre a atividade humana (pp. 132-166). Belo Horizonte : Fabrefactum.

Silva, J. V., \& Corgozinho, J. (2011). Atuação do psicólogo, SUAS/CRAS e Psicologia Social Comunitária : possíveis articulações. Psicologia \& Sociedade, 23, 12-21. doi : 10.1590/ S0102-71822011000400003

Souto, A. P., Lima, K., \& Osorio-da-Silva, C. (2015). Reflexões sobre a metodologia da Clínica da Atividade : diálogo e criação no meio de trabalho. Laboreal, 11(1), 11-22. doi : 10.4000/laboreal. 3962

Vidal-Gomel, C., Delgoulet, C., \& Geoffroy, C. (2014). Competências coletivas e formação em condução de veículos de socorro num contexto de especialização de bombeiros sapadores em França. Laboreal, 10(1), 14-31. doi : 10.4000/laboreal.5133

Wisner, A. (1994). A inteligência no trabalho : textos selecionados de ergonomia. São Paulo : Fundacentro.

Yamamoto, O. H., \& Oliveira, I. (2010). Política Social e Psicologia : uma trajetória de 25 anos. Psicologia : Teoria e Pesquisa, 26, 9-24. doi : 10.1590/S0102-37722010000500002

\section{RESUMOS}

Considerando que na teoria da Clínica da Atividade a presença do gênero profissional e sua constante atualização pelo coletivo de trabalho é a chave para a produção saúde laboral, este estudo objetivou identificar e analisar o gênero dos psicólogos que atuam em centros de referência de assistência social (CRAS) de um município brasileiro e sua relação com o processo de saúde/doença desses profissionais. Realizaram-se encontros com cinco psicólogas que debateram sobre sua atividade a partir do método de oficina de fotos. Para análise de dados utilizou-se a análise do discurso. As condições de trabalho e a ausência de um coletivo profissional constituíram as bases para o adoecimento relatado pelas psicólogas. Contudo, nos encontros permitiu-se intensificar a partilha de saberes, fortalecendo o sentimento de pertencimento coletivo, e afetando na reinterpretação das condições de trabalho. Sugere-se que debates coletivos sobre atividade de trabalho podem contribuir como fator protetivo ao adoecimento de trabalhadores.

Considerando que en la teoría de la Clínica de la Actividad la presencia del género profesional y su constante actualización por el colectivo de trabajo es la clave para la producción de salud laboral, este estudio objetivó identificar y analizar el género de los psicólogos que actúan en centros de referencia de asistencia social de un municipio brasileño y su relación con el proceso de salud/enfermedad de estos profesionales. Se realizaron encuentros con cinco psicólogas que debatieron su actividad utilizando fotos. Para el análisis de los datos se utilizó el análisis del discurso. Las condiciones de trabajo y la ausencia de un colectivo profesional constituyeron las bases para las enfermedades relatadas. En los encuentros se intensificó el intercambio de saberes, fortaleciendo el sentimiento de pertenencia y afectando la reinterpretación de las condiciones de trabajo. Se sugiere que los debates colectivos pueden contribuir como factor protector de enfermedad de los trabajadores. 
Considérant que, par la clinique de l'activité, la présence du genre professionnel et sa mise à jour constante par le collectif de travail constituent la clef de la production de la santé au travail, cette étude voulait analyser le genre des psychologues des services d'assistance sociale d'une municipalité brésilienne et sa relation avec le processus santé-maladie. Des rencontres ont eu lieu avec cinq psychologues qui ont débattu de leur activité à partir de l'usage de photographies. Les données ont été traitées par analyse du discours. Les conditions de travail et l'absence d'un collectif professionnel se sont révélées être à la source des dégradations de santé rapportées. Toutefois, au cours des rencontres, le partage croissant de connaissances a renforcé le sentiment d'appartenance collective, et a infléchi l'interprétation des conditions de travail. Il est suggéré que les débats collectifs sur l'activité professionnelle puissent contribuer à protéger les travailleurs contre les dégradations de leur état de santé

Considering that in the clinic of activity theory the presence of the professional gender and its constant updating by the work collective is the key to the production of occupational health, this study aimed at analyzing the gender of the psychologists who work in social work reference centers of a Brazilian municipality and its relationship with these professionals' health-illness process. Meetings were conducted with five psychologists who debated on their activity from the use of photos. Discourse analysis was used to analyze the data. The conditions of work and the absence of a professional collective were the basis for the illness reported. However, in the meetings it was possible to intensify the sharing of knowledge, strengthening the feeling of collective belonging, and affecting in the reinterpretation of working conditions. It is suggested that collective debates about the work activity can contribute as a protective factor to the sickness of workers.

\section{ÍNDICE}

Palabras claves: psicología, servicios sociales, acción social

Keywords: psychology, social services, social action

Palavras-chave: psicologia, serviços sociais, ação social

Mots-clés: psychologie, services sociaux, action sociale

\section{AUTORES}

\section{IASMIN LIBALDE NASCIMENTO}

Programa de Pós-Graduação em Psicologia da Universidade Federal do Espírito Santo.

Universidade Federal do Espírito Santo. Avenida Fernando Ferrari, 514, Goiabeiras, Vitória, Espírito Santo, 29075-910.

iasmin.libaldenascimento@gmail.com

\section{THIAGO DRUMOND MORAES}

Departamento de Psicologia Social e do Desenvolvimento / Programa de Pós-Graduação em Psicologia da Universidade Federal do Espírito Santo. Universidade Federal do Espírito Santo, Programa de Pós-Graduação em Psicologia. Avenida Fernando Ferrari, 514, Goiabeiras, Vitória, Espírito Santo, 29075-910.

thiago.moraes@ufes.br 